\title{
BMJ Open COVID-19 health and social care access for autistic people: European policy review
}

\author{
Bethany Oakley, ${ }^{1}$ Julian Tillmann (i) , ${ }^{2,3}$ Amber Ruigrok, ${ }^{4}$ Aurélie Baranger, ${ }^{5}$ \\ Christian Takow, ${ }^{5}$ Tony Charman (D) , ${ }^{2,6}$ Emily Jones, ${ }^{7}$ James Cusack, ${ }^{8}$ \\ Mary Doherty, ${ }^{9}$ Pierre Violland, ${ }^{5}$ Agnieszka Wroczyńska, ${ }^{10}$ Emily Simonoff, ${ }^{11}$ \\ Jan K Buitelaar, ${ }^{12,13}$ Louise Gallagher, ${ }^{14}$ Declan G M Murphy, ${ }^{1,15}$ AIMS-2-TRIALS \\ ECRAN \& the AIMS-2-TRIALS Consortium
}

To cite: Oakley B, Tillmann J, Ruigrok A, et al. COVID-19 health and social care access for autistic people: European policy review. BMJ Open 2021;11:e045341. doi:10.1136/ bmjopen-2020-045341

- Prepublication history and additional material for this paper are available online. To view these files, please visit the journal online (http://dx.doi. org/10.1136/bmjopen-2020045341).

BO, JT and AR are joint first authors.

Received 29 September 2020 Revised 28 January 2021 Accepted 17 February 2021

Check for updates

(c) Author(s) (or their employer(s)) 2021. Re-use permitted under CC BY-NC. No commercial re-use. See rights and permissions. Published by BMJ.

For numbered affiliations see end of article.

Correspondence to Dr Bethany Oakley; bethany.oakley@kcl.ac.uk

\section{ABSTRACT}

Background The global COVID-19 pandemic has had an unprecedented impact on European health and social care systems, with demands on testing, hospital and intensive care capacity exceeding available resources in many regions. This has led to concerns that some vulnerable groups, including autistic people, may be excluded from services.

Methods We reviewed policies from 15 European member states, published in March-July 2020, pertaining to (1) access to COVID-19 tests; (2) provisions for treatment, hospitalisation and intensive care units (ICUs); and (3) changes to standard health and social care. In parallel, we analysed survey data on the lived experiences of 1301 autistic people and caregivers.

Results Autistic people experienced significant barriers when accessing COVID-19 services. First, despite being at elevated risk of severe illness due to co-occurring health conditions, there was a lack of accessibility of COVID-19 testing. Second, many COVID-19 outpatient and inpatient treatment services were reported to be inaccessible, predominantly resulting from individual differences in communication needs. Third, ICU triage protocols in many European countries (directly or indirectly) resulted in discriminatory exclusion from lifesaving treatments. Finally, interruptions to standard health and social care left over $70 \%$ of autistic people without everyday support.

Conclusions The COVID-19 pandemic has further exacerbated existing healthcare inequalities for autistic people, probably contributing to disproportionate increases in morbidity and mortality, mental health and behavioural difficulties, and reduced quality of life. An urgent need exists for policies and guidelines on accessibility of COVID-19 services to be updated to prevent the widespread exclusion of autistic people from services, which represents a violation of international human rights law.

\section{INTRODUCTION}

Over 26 million SARS-CoV2 infections (hereafter COVID-19) and 550000 COVID19-related deaths had been confirmed in Europe by the close of 2020, making it one of the worst hit regions worldwide. ${ }^{1}$
Strengths and limitations of this study

- Comprehensive review of regional and national policies and guidelines on access to COVID-19 health and social care services from 15 European countries.

- Large-scale survey of the lived experiences of 1301 individuals from the autism community, capturing real-world COVID-19 health and social care provision.

- Synthesis of policy and survey findings in the context of a multi-disciplinary, participatory collaboration, including autistic people, non-profit autism stakeholder organisations, clinical experts and researchers from across Europe.

- Nuanced analysis and comparison of regional and national service provision is challenging due to variation in health and social care systems and a lack of available policy or survey data in some European countries.

- Self-selection of survey respondents and variation in the impact of COVID-19 across European countries might have introduced response or publication biases that influenced the information available for this study.

During global viral pandemics and public health emergencies, like COVID-19, there is a significant risk that overwhelming and sustained demand for healthcare resources could exceed the capacity of healthcare systems. ${ }^{2}{ }^{3}$ Consequently, mitigation measures to reduce pressure on health and social care systems have been implemented in many regions, including strict national lockdown policies (ie, restrictions on movement) to slow virus transmission. ${ }^{4}$ Nevertheless, within just 1 month of COVID-19 being declared a global pandemic, the European Centre for Disease Prevention and Control reported that many EU countries were experiencing unprecedented demands on testing capacity, personal protective equipment 
(PPE), and hospital and intensive care capacity, far exceeding available resources. ${ }^{5}$ In such situations, disparities in healthcare access are magnified, leading to concerns that some groups of individuals, including autistic people, might be particularly vulnerable to being excluded from services, support and treatment in pandemic situations. ${ }^{6}$

Reports from the United States during the first global peak of COVID-19 infection indicated inequalities in access to COVID-19 services, with one study highlighting that 27 states had adopted 'healthcare rationing' policies that could harm autistic people and those with disabilities (including intellectual disability). ${ }^{7}$ Furthermore, COVID-19 may disproportionately impact autistic people (who represent at least 1\% of European citizens and at least $32 \%$ of whom have a co-occurring intellectual disability $)^{89}$ due to elevated physical health comorbidities and existing healthcare inequalities. For example, physical health conditions are experienced at substantially higher rates by autistic people compared with the general population, including conditions associated with high risk of severe illness from COVID-19 (eg, cardiovascular or immune conditions, diabetes, obesity) ${ }^{10-12}$ In addition, autistic people experience numerous existing barriers to accessing general healthcare, ${ }^{13}$ which may also increase their risk of being excluded from COVID-19 services. These barriers include communication or interpretation difficulties, which can lead to misunderstandings by healthcare providers and reduced involvement of patients in healthcare decision making (and might be exacerbated by mask wearing, which reduces the availability of non-verbal facial cues during interaction); difficulties adjusting to change and novel procedures; sensory sensitivities (eg, around physical examinations, mask wearing); difficulties identifying or describing pains and symptoms; and inconsistent specialist clinician training, awareness and knowledge about autism and intellectual disability. ${ }^{13-15}$ Health providers might also misattribute COVID-19 symptoms to existing medical, mental health or behavioural problems, or autism itself ('diagnostic overshadowing'), increasing the risk of severe disease due to missed or late diagnosis. ${ }^{16}$

Difficulties and delays in accessing COVID-19 services may partly explain why the UK death rate of people with intellectual disability (some of whom are also autistic) increased by $134 \%$ in the period from mid-April to May 2019 compared with 2020, notably higher than in the total population, where deaths increased by $80 \%{ }^{17} 18$ Additionally, at least $40-60 \%$ of confirmed deaths from COVID-19 across European countries with community transmission are believed to have occurred in long-term care facilities, ${ }^{19}$ a proportion of which offer residential care for autistic people. Of further concern, although guidelines around COVID-19 management and intellectual disability were released by the World Health Organization in March $2020^{20}$ and more detailed information has since been published by charities and clinical research teams, ${ }^{21-23}$ the extent to which these recommendations were distributed and implemented within national policies across Europe to safeguard autistic people is unclear.

We collated and reviewed regional or national policies and guidelines from 15 European member states, covering three priority areas: (1) access to COVID-19 testing and screening; (2) provisions for treatment, hospitalisation and access to intensive care units (ICUs); and (3) access to standard health and social care. We considered whether current guidelines (directly or indirectly) discriminate against (or are protective of) autistic people. Furthermore, to capture lived experiences of COVID-19 health and social care provision at the level of the individual, Autism-Europe provided secondary data from a large-scale survey of autistic people and caregivers.

\section{METHODS}

\section{Study design}

AIMS-2-TRIALS is an international public-private partnership that brings together autistic people and their families, researchers and clinicians, charities, industry and pharmaceutical companies to improve understanding of autism and enhance treatment options for autistic people (https://www.aims-2-trials.eu/). To assess COVID-19 health and social care provision for autistic people, according to the priority areas described above, a twostep methodological approach was implemented. First, COVID-19 health and social care policies from 15 European countries were collated and reviewed by researchers, clinicians and non-profit groups from the AIMS-2-TRIALS Clinical Trials and Early Career Researchers in Autism Networks, and a panel of five representatives from the autism community.

Second, Autism-Europe provided de-identified secondary data from their large-scale survey of the impact of COVID-19 on 1301 autistic people and caregivers. An overview of the European countries represented in this review is presented in figure 1 and Autism-Europe respondent characteristics in online supplemental table 1.

\section{Materials and procedures}

Review of European COVID-19 policy and guidelines

COVID-19-related policies and guidelines from 15 European countries (figure 1) were assessed using a common review template (please see online supplemental material $1)$, indexing three priority areas: access to testing and screening; access to treatment, hospital and intensive care resources; and changes to existing health and social care. To be included, policies and guidelines had to be publicly available (ie, online/open access) and published between March and July 2020. A full list of included documents is provided in online supplemental table 2, with source of access specified.

Policies and guidelines were collated and translated into English by a panel of 30 AIMS-2-TRIALS early career autism researchers and five representatives from the autism community. In addition, documents were reviewed 


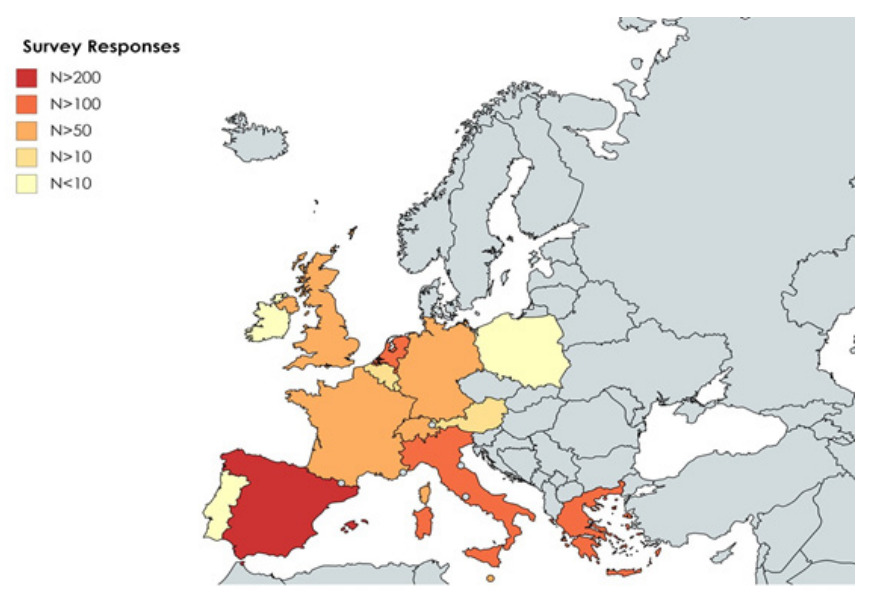

Figure 1 Schematic highlighting the 15 European countries included in this study, colour coded by number of AutismEurope survey responses from each region: Spain, $\mathrm{n}=304$; Italy, $\mathrm{n}=192$; Greece, $\mathrm{n}=165$; the Netherlands, $\mathrm{n}=143$; Switzerland, $n=144$; France, $n=86$; United Kingdom, $n=66$; Germany, $n=60$; Malta, $n=53$; Belgium, $n=34$; Luxembourg, $n=33$; Austria, $n=12$; Ireland, $n=5$; Poland, $n=3$; Portugal, $n=1$.

by clinicians with extensive experience in autism diagnosis and intervention, who provided expert commentary.

\section{Lived experiences from the autism community}

As noted in the Introduction, where specific guidance has been published, the extent to which recommendations for supporting autistic people and those with intellectual disability have been implemented in everyday practice is unclear. Thus, alongside our policy review, AutismEurope (an international, non-profit organisation: https://www.autismeurope.org/) also provided de-identified secondary data from their independent, large-scale survey of experiences of the COVID-19 pandemic from the autism community.

For the purposes of this review, we included AutismEurope survey responses from the 15 countries for which we also had access to published policy or guidelines. We excluded respondents who were not autistic, or relatives/ caregivers (as the identity of 'other' respondents were not clearly defined), and those who opened but did not answer survey questions. This resulted in a final convenience sample of 1301: 346 autistic people and 955 caregivers. Please see online supplemental table 1 for survey demographics.

Survey items requested from Autism-Europe for the purpose of this review are documented in online supplemental table 3. The survey was disseminated publicly online between 7 April and 31 May 2020, in 10 languages, with participants recruited via Autism-Europe, UK autism charities and social media. Administration of the survey was conducted under the 'Rights, Equality and Citizenship programme 2014-2020', funded by the European Commission. Respondents were notified of the AutismEurope GDPR policy that responses would be used for the development of policy recommendations, and gave written permission for the publication of their anonymised quotations, which were included for illustrative purposes.

\section{Public and patient involvement}

Representatives from the autism community, and charities Autism-Europe and Autistica, were involved as active research partners in all aspects of the research through identifying priority areas for policy review, collating and reviewing policy guidelines in selected countries, interpreting findings, making recommendations for policy guidance, and editing or co-authoring the manuscript. Autism-Europe independently designed the survey content and collated all responses.

\section{RESULTS \\ Review of European COVID-19 policy or guidelines (March- July 2020) \\ Accessibility of COVID-19 testing and screening}

First, we considered guidance on access to COVID-19 tests, particularly in the context of testing shortages. As explicitly acknowledged in documentation released by several European regions reviewed in this study-including the UK, the Netherlands and Belgium ${ }^{24-26}$ — those with relevant physical comorbidities and/or living in residential care meet criteria for priority COVID-19 testing. This guidance is relevant for autistic people, given a high proportion experience physical health comorbidities that are associated with increased risk of developing severe disease on contracting COVID-19, including cardiovascular or respiratory illness, autoimmune conditions, diabetes, obesity and hypertension.

Second, approximately $5-25 \%$ of autistic people live in residential care (ie, higher intensity nursing or large group homes) and up to a further $27 \%$ in supported accommodation (ie, lower intensity congregate care settings in the community), with upper bound estimates referring to those with co-occurring intellectual disability. ${ }^{27}$ This is notable because the transmission rate of COVID-19 in residential care settings is high due to factors such as care staff interacting with multiple residents throughout the day; global shortages of PPE and testing for care staff; difficulties for some individuals with strict adherence to personal hygiene practices; and impracticalities of maintaining physical distancing (eg, if residents require personal care).$^{28} 29$

Despite existing evidence of increased risk of poor outcomes from COVID-19 for autistic people, our review indicated that they have not been routinely specified for priority access to testing across Europe. For instance, early in the COVID-19 pandemic, many regions with testing shortages initially prioritised essential workers and those hospitalised with suspected COVID-19 symptoms. $^{30}$ In the UK and Ireland, care home residents (including those who were asymptomatic) were not officially added to the list for priority access to COVID-19 testing until 29 and 17 April 2020, respectively, at least 
2 months after the first confirmed COVID-19 cases in these regions. ${ }^{26}{ }^{31}$ Similarly, other countries that did not initially identify individuals in residential care settings as priority for testing, including the Netherlands and Belgium, ${ }^{24}{ }^{25}$ now prioritise these groups; the Netherlands is the only country to directly prioritise individuals with serious behavioural problems in residential care for testing.

However, we did not identify any additional published guidance, or strategies specifically for enhancing accessibility of testing for autistic people across any other country reviewed in this study. For instance, even in the countries identified above where individuals with certain physical comorbidities and those living in 'high risk' settings were prioritised for access to testing in case of shortages, there was no guidance published for those living in supported accommodation and the community. A lack of guidance was also identified for enhancing the tolerability (and thus accessibility) of test procedures for autistic people. For example, sensory sensitivities and difficulties around uncertainty and changes in routine are highly associated with autism, ${ }^{3233}$ and COVID-19 diagnostic tests frequently involve nasal and throat swabs or aspiration, ${ }^{34}$ use of necessary PPE (a potential sensory and communication barrier), long waiting times and travel to an unfamiliar location-sometimes without the option to be accompanied by a caregiver.

\section{Access to treatment or hospitalisation}

Next, we reviewed current recommendations for the treatment and admission to hospital of autistic people who have COVID-19. Findings first highlighted that guidance from several European countries, including Belgium, Italy and the Netherlands, currently recommends that autistic people and those with behavioural problems are treated for COVID-19 within existing designated specialist neurodevelopmental or neuropsychiatric pathways, rather than general hospital settings. ${ }^{35} 36$

This approach may have some benefit in access to a greater range of specialist staff and resources to adequately support individuals with additional needs, as well as providing more flexibility around some regulations (eg, allowing visitation by a caregiver or support person, with appropriate hygiene measures in place).

Nevertheless, in an open letter to EU leaders, the European Disability Forum specifically recommended that "persons with disabilities should not be segregated into separate facilities, where healthcare for COVID-19 is often of a lower standard' ${ }^{37}$ Examples of concerns about COVID-19 care provision in neurodevelopmental or psychiatric pathways include shortages of staff with medical or surgical and psychiatric expertise and experience. In addition, there are challenges for controlling infection spread in neurodevelopmental or psychiatric inpatient settings due to factors like close contact between patients and care providers and shortages of PPE, for which general hospitals may be prioritised. ${ }^{38}$

\section{Access to intensive care}

Our review indicated that-where officially documented-interpretation of ICU triage protocols and policies could pose a barrier to equitable care and access to lifesaving treatments (please see table 1).

For example, several European countries with published triage protocols recommend the consideration of 'functional status' and/or the use of 'frailty assessments', including the UK, Ireland, France, the Netherlands, Italy, Belgium, Austria and Germany. ${ }^{39-47}$ These assessments were originally designed with reference to elderly populations to determine individuals with very poor prognosis for recovery from their current illness. ${ }^{48}$ Despite this, concerns have been raised over ambiguity in some current guidance on the application and interpretation of frailty assessments, whereby the support needs of some autistic people may be conflated with 'frailty'. ${ }^{37} 490$ As an example, frailty assessments refer to an individual's dependency on others for support with daily care needs and personal care. Similarly, the assessment of functional status often includes quality of life outcomes, which are known to vary considerably among autistic people but may also be broadly underestimated because of a reliance on 'neurotypical' indicators of well-being. ${ }^{51}$

In light of these concerns-and in response to challenges by advocacy groups and a proposed judicial review $^{5253}$-on 25 March 2020, the UK National Institute for Health and Care Excellence amended their recommendations to specify that frailty assessments should not be used for younger people or autistic people and those with intellectual disability. ${ }^{54}$ They also added weblinks to ethical guidance from medical associations (9 April 2020) and stated that-where they are appropriatefrailty assessments should be recorded in the patient's medical record for transparency (29 April 2020). Similar clarifications on the lack of suitability of frailty assessment for those with intellectual disability have been published in the Netherlands. ${ }^{56}{ }^{57}$ Nevertheless, such measures to prevent the misapplication of frailty assessments to autistic people have not been implemented systematically across European countries.

Moreover, the Working Group of Bioethics of the Spanish Society of Intensive, Critical Medicine and Coronary Units published triage guidance that explicitly specifies 'severe baseline cognitive impairment' as an exclusion criterion for ICU care. ${ }^{58}$ This recommendation is based on previous advice published in 2010 by the European Society of Intensive Care Medicine Task Force for ICU triage during an influenza epidemic, further specifying the exclusion of 'a patient who is unable to perform activities of daily living due to cognitive impairment or is institutionalised due to cognitive impairment'. ${ }^{59} 60$ Similar guidance from the COVID-19 Paris region recommends attention to a patient's previous condition, including neurocognitive status-mildly or severely impaired cognitive functions. ${ }^{44}$

These criteria (and ambiguity in their intended application to real-world clinical practice) plainly increase the 


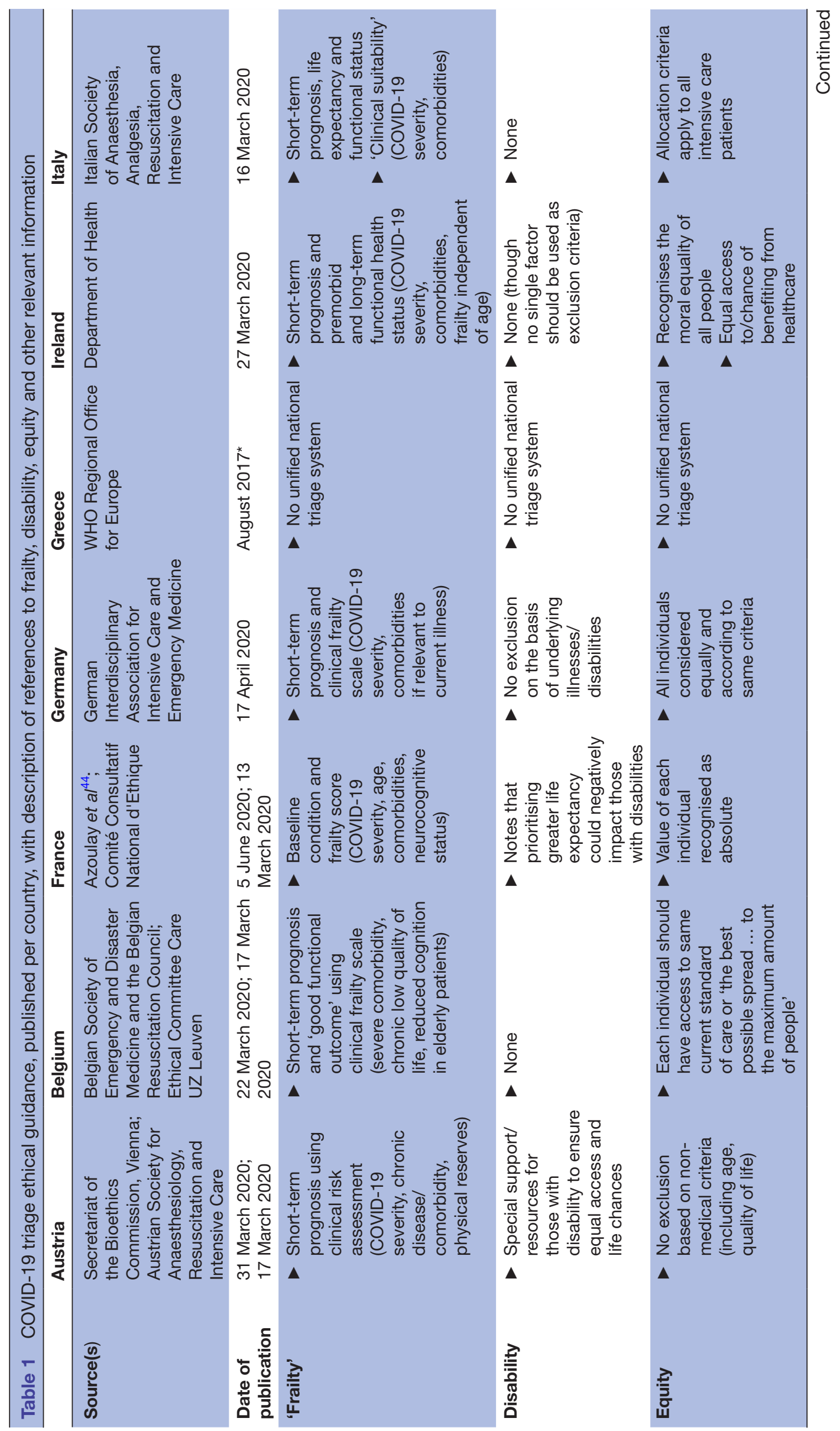




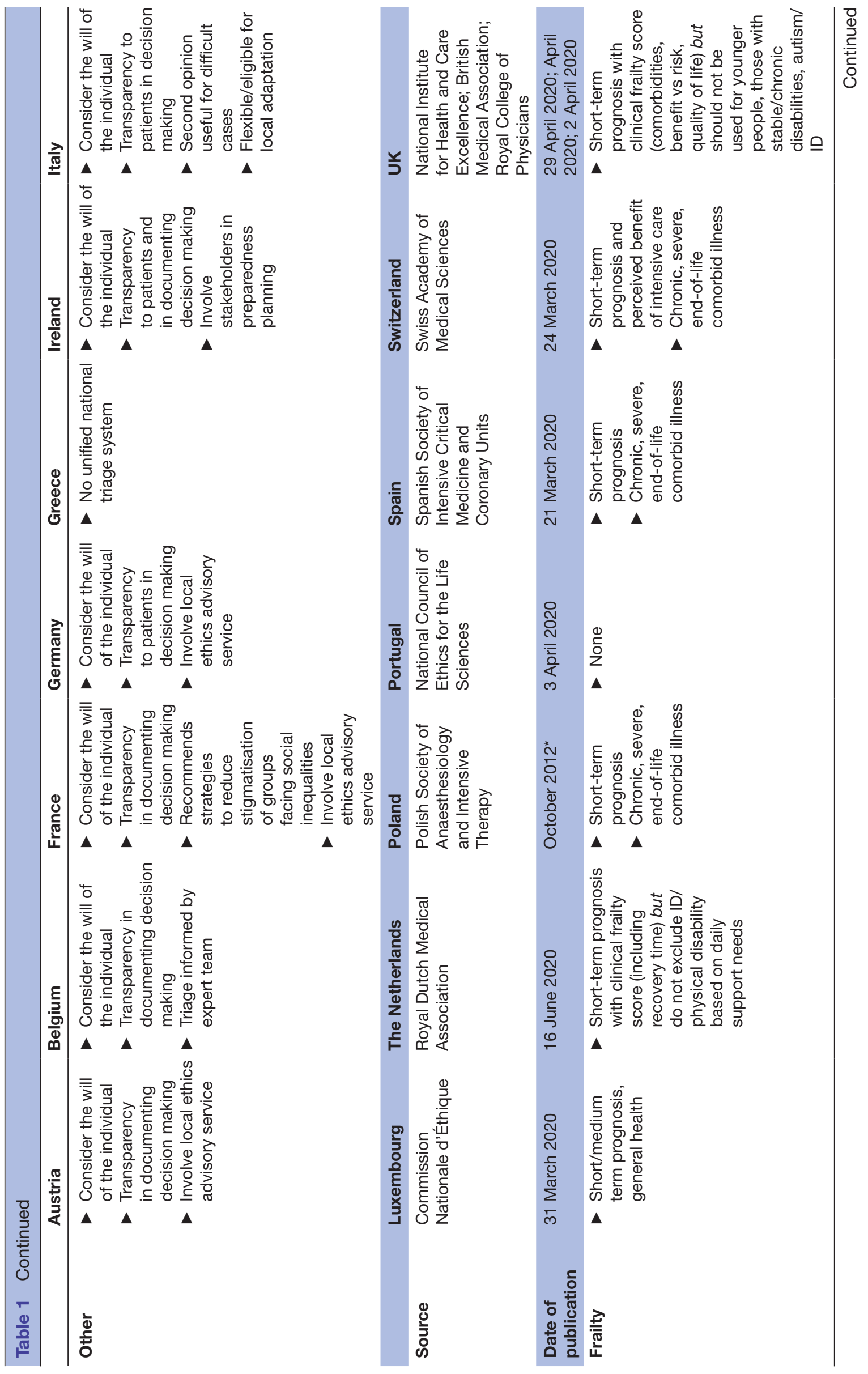




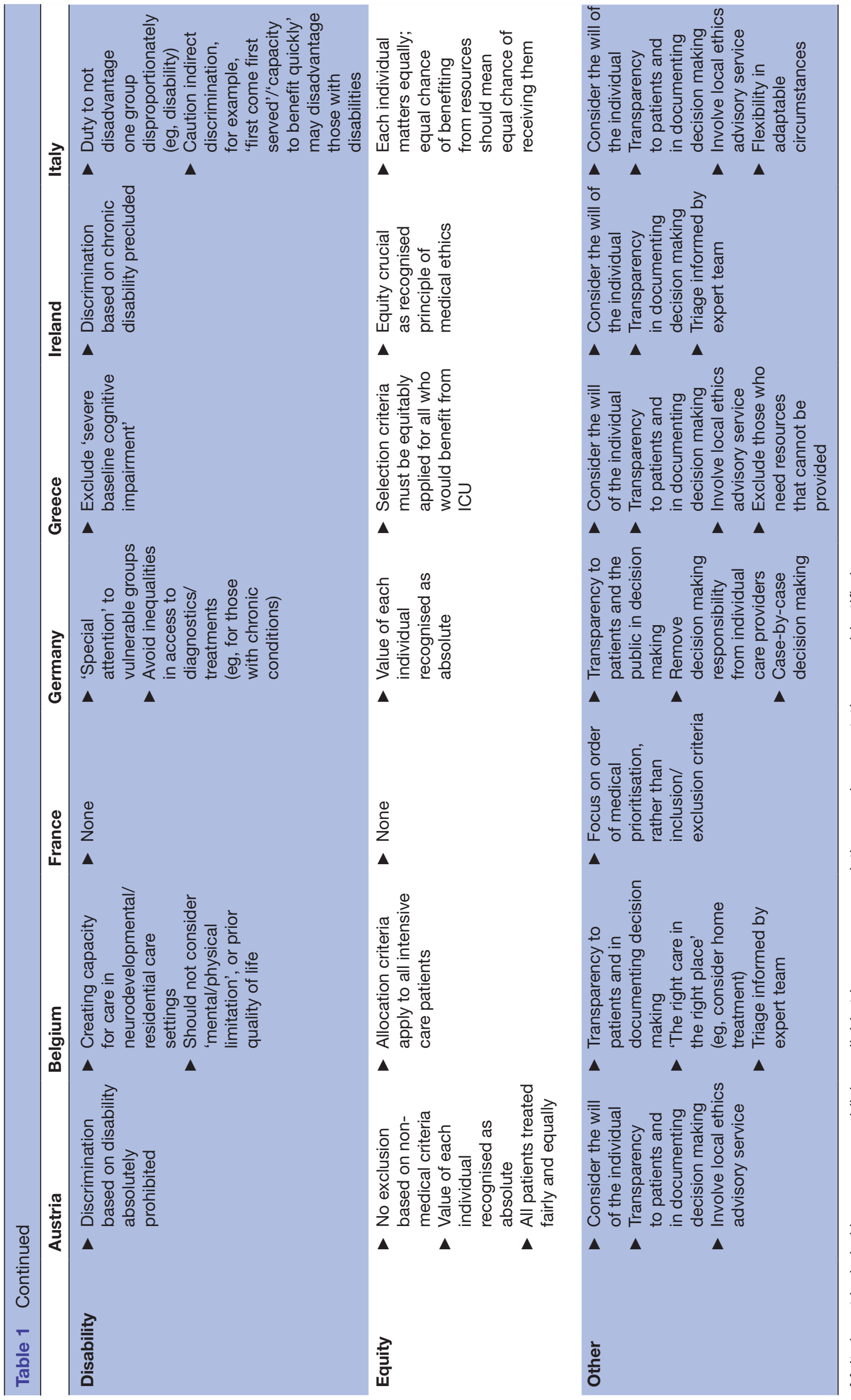


potential for discriminatory exclusion of autistic people, especially those with co-occurring intellectual disability, and are incompatible with international human rights laws (also emphasised by Spanish reports ${ }^{61}{ }^{62}$ ); yet, they may be informing clinical decision making. ${ }^{63}$

\section{Access to existing health and social care services}

Overall, our review would suggest that the impact of COVID-19 has emphasised longstanding pressures on health and social care systems across Europe and preexisting healthcare inequalities for autistic people. The first trend observed across all regions reviewed has been the abrupt interruption of usual social support and intervention services to prevent infection spread. While an important safety precaution, without appropriate mitigation measures in place, for some individuals, services have ceased altogether. ${ }^{64}$

Usual health and social care services for autistic people have been particularly impacted in three key areas. First, many services were already stretched in non-pandemic times, including autism diagnostic services, for which average waiting times can be well over ayear (a maximum of 13 weeks is recommended by the UK National Institute for Health and Care Excellence).$^{65}$ Considered 'nonessential' in light of the COVID-19 pandemic, cancelled or postponed diagnostic appointments may further delay autistic people accessing needs-based support (eg, mental health interventions), which could be contingent on receiving a formal diagnosis.

Second, many community-based services across Europe (eg, day services, workshops, supported employment) are provided by the private sector and non-profit organisations. These organisations have reported experiencing acute financial instability due to COVID- $19^{66}$ and are not always eligible to claim reimbursement for appointments that have been shifted to online delivery (though see flexible legislation from Belgium) ${ }^{67}$ meaning some have been forced to close completely. ${ }^{68}$ As a result, for some autistic people, relatives and other caregivers are currently the only available support people.

For those living in residential care settings, with low capacity for testing and PPE provisions, restrictions have been imposed on visitation from relatives or other caregivers. These restrictions may include a complete ban on visitation, limits on the number of visitors and/or time limits on visitation. ${ }^{35}{ }^{69-71}$ These measures are designed to prevent infection spread in 'high risk' long-term care facilities. However, loss of contact with relatives or caregivers (also constituting a change in routine) could cause distress for autistic people and increase uncertainty and loneliness. Consequently, necessary restrictions on visitation to residential care settings must be balanced with flexible options for alternative communication, such as regular and consistent access to video or telephone contact $^{72}$-though it should be acknowledged that these options are not sufficient or appropriate for all individuals.
Finally, for those receiving community-based care, we also identified evidence from the UK of 'easements' to publicly funded adult social care in response to COVID$19{ }^{73}$ These easements were introduced to relieve pressure on social care services and assist with prioritising support for those in highest need, by reducing the duty to carry out detailed assessments of individual care and support or financial needs, and reducing the duty to prepare or review individual care and support plans. We identified no published evidence to date that any local authorities in England have yet exercised social care easements. ${ }^{74}$ Nevertheless, it is essential that this situation continues to be closely monitored to ensure that those in need receive adequate support, particularly given the significant lack of reliable data gathered on community-based health and social care provision across Europe. ${ }^{75}$

\section{Lived experiences from the autism community (April-May 2020)}

Accessibility of COVID-19 testing and screening

Corresponding to findings from our policy reviewdetailed above-the results from Autism-Europe's survey of autistic people and caregivers (see table 2) also indicated that despite being considered at increased risk of poor outcomes from COVID-19, there was a lack of accessibility to COVID-19 testing.

For instance, $26 \% \quad(n=327)$ of autistic people represented in Autism-Europe's survey were reported to be considered at high risk from COVID-19. Nevertheless, of the $5 \%$ of autistic people who accessed a COVID-19 test, $25 \%(\mathrm{n}=13)$ felt they did not receive, or were unsure whether they had received, adequate accessible information about the test procedure (table 2). Furthermore, only $39 \% \quad(\mathrm{n}=22)$ were provided with autism-specific reasonable adjustments (eg, allowed to be accompanied by a support person; tested in a quiet space). These issues were particularly emphasised by the report of one parent of a child with autism, who commented:

I wanted to get my son tested but there was no way to get this done without sedating him. This was not provided by the doctors and it was such a traumatic experience ended up [sic] not doing the test after 1.5 hours of trying and quarantined instead for 2 weeks.

\section{Access to treatment, hospitalisation and intensive care}

Additionally, survey data showed that a proportion of autistic people also experienced difficulties accessing COVID-19 outpatient and inpatient treatment services.

Of the $2 \% \quad(n=28)$ of autistic people captured by Autism-Europe's survey who required COVID-19 treatment, around half reported access difficulties $(n=12)$, mostly accounted for by inaccessibility of the process of contacting healthcare providers $(n=9$; for example, contact by telephone was required):

Similarly, communication difficulties can represent a major barrier for receiving quality inpatient treatment 
Table 2 Autism-Europe survey responses for access to COVID-19 health and social care services for people with autism. Data are numbers (\%)

\begin{tabular}{|c|c|c|c|c|c|c|c|c|c|}
\hline & \multicolumn{3}{|c|}{ Overall response } & \multicolumn{3}{|c|}{ Autistic person response } & \multicolumn{3}{|c|}{ Caregiver response } \\
\hline & Yes & No & Unsure & Yes & No & Unsure & Yes & No & Unsure \\
\hline $\begin{array}{l}\text { High COVID-19 risk (autistic } \\
\text { person) }\end{array}$ & $\begin{array}{l}327 \\
(26)\end{array}$ & $\begin{array}{l}795 \\
(63)\end{array}$ & $\begin{array}{l}133 \\
(11)\end{array}$ & $\begin{array}{l}90 \\
(27)\end{array}$ & $\begin{array}{l}213 \\
(63)\end{array}$ & $\begin{array}{l}33 \\
(10)\end{array}$ & $\begin{array}{l}237 \\
(26)\end{array}$ & $\begin{array}{l}582 \\
(63)\end{array}$ & $\begin{array}{l}100 \\
(11)\end{array}$ \\
\hline Tested for COVID-19 & $\begin{array}{l}56 \\
(5)\end{array}$ & $\begin{array}{l}1095 \\
(95)\end{array}$ & $\begin{array}{l}1 \\
(0)\end{array}$ & $\begin{array}{l}13 \\
(4)\end{array}$ & $\begin{array}{l}295 \\
(96)\end{array}$ & $\begin{array}{l}0 \\
(0)\end{array}$ & $\begin{array}{l}43 \\
(5)\end{array}$ & $\begin{array}{l}800 \\
(95)\end{array}$ & $\begin{array}{l}1 \\
(0)\end{array}$ \\
\hline $\begin{array}{l}\text { Accessible information-COVID-19 } \\
\text { test }\end{array}$ & $\begin{array}{l}40 \\
(76)\end{array}$ & $\begin{array}{l}10 \\
(19)\end{array}$ & $\begin{array}{l}3 \\
(6)\end{array}$ & $\begin{array}{l}7 \\
(58)\end{array}$ & $\begin{array}{l}4 \\
(33)\end{array}$ & $\begin{array}{l}1 \\
(8)\end{array}$ & $\begin{array}{l}33 \\
(80)\end{array}$ & $\begin{array}{l}6 \\
(15)\end{array}$ & $\begin{array}{l}2 \\
(5)\end{array}$ \\
\hline $\begin{array}{l}\text { Reasonable adjustments- } \\
\text { COVID-19 test }\end{array}$ & $\begin{array}{l}22 \\
(39)\end{array}$ & $\begin{array}{l}31 \\
(54)\end{array}$ & $\begin{array}{l}4 \\
(7)\end{array}$ & $\begin{array}{l}6 \\
(30)\end{array}$ & $\begin{array}{l}11 \\
(55)\end{array}$ & $\begin{array}{l}3 \\
(15)\end{array}$ & $\begin{array}{l}16 \\
(43)\end{array}$ & $\begin{array}{l}20 \\
(54)\end{array}$ & $\begin{array}{l}1 \\
(3)\end{array}$ \\
\hline Required COVID-19 treatment & $\begin{array}{l}28 \\
(2)\end{array}$ & $\begin{array}{l}1112 \\
(96)\end{array}$ & $\begin{array}{l}13 \\
(1)\end{array}$ & $\begin{array}{l}7 \\
(2)\end{array}$ & $\begin{array}{l}296 \\
(96)\end{array}$ & $\begin{array}{l}5 \\
(2)\end{array}$ & $\begin{array}{l}21 \\
(2)\end{array}$ & $\begin{array}{l}816 \\
(97)\end{array}$ & $\begin{array}{l}8 \\
(1)\end{array}$ \\
\hline Difficulties accessing treatment & $\begin{array}{l}12 \\
(43)\end{array}$ & $\begin{array}{l}15 \\
(54)\end{array}$ & $\begin{array}{l}1 \\
(4)\end{array}$ & $\begin{array}{l}5 \\
(71)\end{array}$ & $\begin{array}{l}2 \\
(29)\end{array}$ & $\begin{array}{l}0 \\
(0)\end{array}$ & $\begin{array}{l}7 \\
(33)\end{array}$ & $\begin{array}{l}13 \\
(62)\end{array}$ & $\begin{array}{l}1 \\
(5)\end{array}$ \\
\hline $\begin{array}{l}\text { Difficulties contacting treatment } \\
\text { provider }\end{array}$ & $\begin{array}{l}9 \\
(75)\end{array}$ & $\begin{array}{l}3 \\
(25)\end{array}$ & $\begin{array}{l}0 \\
(0)\end{array}$ & $\begin{array}{l}3 \\
(60)\end{array}$ & $\begin{array}{l}2 \\
(40)\end{array}$ & $0(0 \%)$ & $\begin{array}{l}6 \\
(86)\end{array}$ & $\begin{array}{l}1 \\
(14)\end{array}$ & $\begin{array}{l}0 \\
(0)\end{array}$ \\
\hline $\begin{array}{l}\text { Require daily or occasional } \\
\text { support }\end{array}$ & $\begin{array}{l}882 \\
(68)\end{array}$ & $\begin{array}{l}398 \\
(31)\end{array}$ & $\begin{array}{l}21 \\
(2)\end{array}$ & $\begin{array}{l}184 \\
(53)\end{array}$ & $\begin{array}{l}146 \\
(42)\end{array}$ & $\begin{array}{l}16 \\
(5)\end{array}$ & $\begin{array}{l}698 \\
(73)\end{array}$ & $\begin{array}{l}252 \\
(26)\end{array}$ & $\begin{array}{l}5 \\
(1)\end{array}$ \\
\hline Usual daily support stopped & $\begin{array}{l}595 \\
(71)\end{array}$ & $\begin{array}{l}211 \\
(25)\end{array}$ & $\begin{array}{l}31 \\
(4)\end{array}$ & $\begin{array}{l}73 \\
(42)\end{array}$ & $\begin{array}{l}84 \\
(48)\end{array}$ & $\begin{array}{l}17 \\
(10)\end{array}$ & $\begin{array}{l}522 \\
(79)\end{array}$ & $\begin{array}{l}127 \\
(19)\end{array}$ & $\begin{array}{l}14 \\
(2)\end{array}$ \\
\hline $\begin{array}{l}\text { High COVID-19 risk (support } \\
\text { person) }\end{array}$ & $\begin{array}{l}279 \\
(33)\end{array}$ & $\begin{array}{l}409 \\
(49)\end{array}$ & $\begin{array}{l}149 \\
(18)\end{array}$ & $\begin{array}{l}50 \\
(29)\end{array}$ & $\begin{array}{l}94 \\
(54)\end{array}$ & $\begin{array}{l}30 \\
(17)\end{array}$ & $\begin{array}{l}229 \\
(35)\end{array}$ & $\begin{array}{l}315 \\
(48)\end{array}$ & $\begin{array}{l}119 \\
(18)\end{array}$ \\
\hline Second support person available & $\begin{array}{l}247 \\
(30)\end{array}$ & $\begin{array}{l}523 \\
(63)\end{array}$ & $\begin{array}{l}67 \\
(8)\end{array}$ & $\begin{array}{l}44 \\
(25)\end{array}$ & $\begin{array}{l}107 \\
(61)\end{array}$ & $\begin{array}{l}23 \\
(13)\end{array}$ & $\begin{array}{l}203 \\
(31)\end{array}$ & $\begin{array}{l}416 \\
(63)\end{array}$ & $\begin{array}{l}44 \\
(7)\end{array}$ \\
\hline $\begin{array}{l}\text { Accessible information-COVID-19 } \\
\text { public health }\end{array}$ & $\begin{array}{l}421 \\
(35)\end{array}$ & $\begin{array}{l}557 \\
(46)\end{array}$ & $\begin{array}{l}234 \\
(19)\end{array}$ & $\begin{array}{l}119 \\
(36)\end{array}$ & $\begin{array}{l}117 \\
(35)\end{array}$ & $\begin{array}{l}94 \\
(28)\end{array}$ & $\begin{array}{l}302 \\
(34)\end{array}$ & $\begin{array}{l}440 \\
(50)\end{array}$ & $\begin{array}{l}140 \\
(16)\end{array}$ \\
\hline
\end{tabular}

in general hospital settings, as noted by one person with autism:

I had to be hospitalised with acute abdominal cramps. On the spot, the nursing staff took my temperature and, worried, they did not know what to do: whether to put me in a separate room, because I could have COVID-19, or not. I was in the Emergency Room for 6 hours, the doctors deliberated my case, and in the end I was not tested. During the whole process, I was mute, paralysed. So I wonder if there is a way to communicate with the medical professionals about everyone's situation without adding to the medical professionals' workload.

Moreover, concerns regarding inequalities in access to COVID-19 services could pose a barrier for seeking treatment, with one autistic Autism-Europe survey respondent revealing:

I am also afraid that as a mentally impaired [sic] recipient of a disability pension, during possible triage I will be rated worse than those capable of working of the same age (ableism) should there be shortages of medical care.

This comment highlights the importance of ensuring that public health information is made accessible for the autism community, with $65 \%(\mathrm{n}=791)$ of Autism-Europe survey respondents being unaware or unsure of accessible information about current COVID-19 measures.

Access to existing health and social care services

Finally, reflecting the impact of the abrupt interruption of usual social support and intervention services on autistic people, $71 \%(\mathrm{n}=595)$ of Autism-Europe survey respondents included in this review indicated that their usual support services had been stopped due to COVID19. This is notable given that approximately one third of those surveyed indicated that they required daily support $(35 \% ; n=451)$ and one third required occasional support with daily life activities $(33 \% ; n=431)$.

In addition, $33 \%(\mathrm{n}=279)$ of Autism-Europe survey respondents stated that their usual support person was also at increased risk of COVID-19\% and 63\% ( $\mathrm{n}=523)$ reported they did not have access to another support person if their usual caregiver became infected.

\section{DISCUSSION}

\section{Summary of key findings and recommendations}

We reviewed COVID-19 health and social care access for autistic people across 15 European member states, based on published policies or guidelines and results from a large-scale survey of over 1300 autistic people and caregivers. Our findings highlighted several issues regarding 
COVID-19 service access for autistic people that require rapid consideration, in terms of testing and screening; accessibility of treatment, hospitalisation and ICU care; and changes to standard health and social care provision.

Specifically, we identified (1) failure to prioritise and provide adequate adaptations to promote access to testing, despite elevated risk of severe COVID-19 disease due to commonly co-occurring physical health problems; (2) barriers for accessing treatment and hospitalisation (eg, alternative communication needs) and ICU triage protocols that directly or indirectly (ie, through their ambiguity) discriminate against those with additional needs; and (3) abrupt interruptions to existing service provision (eg, mental health or community-based services) without appropriate mitigation measures, further exacerbated by longstanding pressures on health and social care. Considering these issues, we formulated a set of recommendations for policy and clinical practice to improve health and social care access for autistic people in pandemic situations and other public health emergencies (box 1).

\section{Enhancing accessibility of COVID-19 testing and screening}

As outlined above, our first key finding was a failure to prioritise and systematically provide adequate adaptations to promote access to testing for autistic people. COVID-19 strategies published by the World Health Organization and European Commission emphasise the critical importance of testing people with suspected COVID-19 so that people with confirmed infection can be isolated and their close contacts traced. ${ }^{76}{ }^{77}$ COVID-19 testing strategies and capacity have varied among European countries. However, broadly, infrastructure limitations (eg, manual processing of test data, financial) and supply shortages mean that testing capacity has fallen below growing demand across the EU. ${ }^{78}$ According to the World Health Organization and European Commission, in the case of insufficient testing capacity, priority groups for rapid testing in EU countries should include those at increased risk of developing severe disease (including acute respiratory illness and elderly populations with chronic health conditions); symptomatic health and social care workers; and those in closed settings, such as residential care homes ${ }^{76}$ — criteria highly relevant to a proportion of autistic people.

However, it must be acknowledged that many autistic people experience additional barriers that could increase their risk of poor outcome from COVID-19, which should therefore also be explicitly acknowledged in policy and clinical documentation and guidance. These barriers include atypical symptom presentation (which may partly reflect high comorbidity burden and also lead to relevant comorbid physical health risk factors going undiagnosed), diagnostic overshadowing, and difficulties identifying and describing symptoms (see reviews of interoception difficulties and alexithymia in autism),${ }^{80} 81$ which could lead to late or missed diagnosis, or misdiagnosis, and difficulties gaining access to appropriate treatments.
Box 1 Recommendations for an aligned European strategy for reducing inequalities in access to health and social care services for autistic people and those with intellectual disability in pandemic situations

\section{Policy recommendations}

1. Policy documentation should explicitly outline strategies for promoting equitable access to testing and screening for autistic people, including clinical guidance on identifying symptoms (given evidence for atypical symptom presentation, diagnostic overshadowing and high comorbidity burden), providing accessible inpatient and outpatient care and enhancing the accessibility of testing procedures by providing preparatory materials and considering flexible test procedures (eg, saliva vs swab testing). Autistic people with physical health comorbidities and those living in 'high risk' settings for disease transmission, such as residential care and supported accommodation, should be considered for priority access to proactive testing and screening, even when apparently asymptomatic.

2. If hospital admission is necessary, autistic people should receive the necessary accommodations and support to facilitate access to the same resources and standard of care as other individuals. This support may include the development of consistent policies to ensure: accessible information and communication methods; frequent consultation between the individual, their families (if appropriate) and care provider(s); formal guidance and training to support care providers from all specialities; greater flexibility in care provision.

3. Triage protocols across Europe require urgent review and update, in consultation with stakeholders (eg, intensive care and autism communities), to inform an aligned European strategy on the fair allocation of resources in public health emergencies that does not explicitly or inadvertently discriminate against any individual or groups of individuals on the grounds of pre-existing characteristics or difficulties.

4. The impact of COVID-19 on health and social care service provision should be comprehensively reviewed to inform mitigation or contingency plans for the safe and effective delivery of services in the short and longer term. In particular, the collection of high quality and reliable data on health and social care provision will support a targeted approach for identifying (cost-)effective strategies for restructuring and investment in health and social care, likely including greater flexibility in service provision (eg, telehealth, needs vs diagnosis based support) and community based care.

\section{Clinical practice recommendations}

1. Mandatory provision of alternative, accessible and easy-read healthcare information and communication toolkits. ${ }^{111} 112$

2. Mandatory consultation with autistic people to provide prior information about themselves, their preferences and healthcare needs, in case they become unable to communicate on admission to hospital (eg, the COVID-19 'Grab and Go' Guide). ${ }^{113}$ This is essential to prevent healthcare decisions being made without the consent of patients and their families, as exemplified by the concerning application of COVID-19 'Do not attempt resuscitation' orders to the notes of some autistic people, without consultation. ${ }^{114}$

3. Mandatory, regularly updated formal guidelines and training for all healthcare providers, co-developed with autistic people and supported by access to specialist providers like learning disability or psychiatric liaison staff. ${ }^{3563115}$

4. Introducing flexibility to some regulations (if appropriate), such as allowing a caregiver or support person to accompany the individual into hospital, following all necessary infection control procedures

Continued 


\section{Box 1 Continued}

(already in place in regions of the UK, Germany and the Netherlands, according to clinician reviews) and making reasonable adjustments to ensure this flexibility is fulfilled in real-world clinical settings.

Considering these issues, our first recommendation for an aligned European strategy for responding to pandemic situations is that - in the case of testing shortages-autistic people should be considered for priority access to testing if they are living in 'high risk' settings for disease transmission (even when apparently asymptomatic), such as residential care and supported accommodation (box 1).

To further promote equitable access to testing, it is important to also consider flexible testing methods to remove barriers for autistic people, who often experience sensory sensitivities associated with procedures like swab tests. Currently, if an individual is symptomatic but cannot be tested then good public health practice would be to treat the individual as a suspected case, which could result in enhanced (and potentially unnecessary) restrictions being disproportionately imposed on some groups of individuals with additional needs. Examples of methods for enhancing the accessibility of testing procedures include the provision of high-quality preparatory materials, such as social stories and videos, available in different languages and easy-read formats, to demonstrate the testing procedure in advance (for examples, please see AsIAm ${ }^{87}$ ). Moreover, for those who cannot tolerate swab testing, the use of non-invasive saliva sampling could be considered and can be readily performed at home. Of note, the utility of the saliva method for COVID-19 testing has been demonstrated ${ }^{8283}$ and is already approved by the US Food and Drug Administration, and in use in some European countries, including Germany.

\section{Enhancing access to treatment, hospitalisation and intensive care}

Enhancing the accessibility of COVID-19 testing, particularly in cases of shortage, has added potential to reduce the proportion of autistic people who require any treatment, hospitalisation or intensive care by reducing viral transmission. This is significant given that autistic people often have suboptimal experiences of accessing healthcare and hospital admission, ${ }^{13-15}$ and experience higher odds of death in hospital. Furthermore, the resources required to adequately support autistic people during hospitalisation are likely to be considerably stretched in pandemic situations. ${ }^{84}$ There have been (and are currently) concerns across Europe about the 'surge' capacity of healthcare systems to cope with acute increases in patients requiring hospital and intensive care beds. ${ }^{85}$

Increasing capacity and investing in resilience planning should be the primary response for ensuring equal access to hospital and intensive care resources, across the population. Nevertheless, it is necessary for formal guidance to be provided for clinicians on the fair allocation of resources in times of scarcity. For example, officially documented intensive care triage protocols for public health emergencies, combined with designated local ethics panels within healthcare settings, are essential to ensure that individual clinicians are never responsible for taking or implementing triage decisions and to avoid conflicts of interest. ${ }^{86} 87$ On the grounds of fundamental human rights, it is paramount that this guidance does not discriminate against individuals or groups of individuals on any illegitimate grounds, including developmental difference or disability, as highlighted in a recent open letter by the International Disability Alliance ${ }^{88-90}$ and reflected in the ICU triage protocols of eight of the 14 European regions reviewed (please see table 1).

Consequently, our second set of recommendations relate to proper resourcing and care planning, which must be implemented to support autistic people who develop severe COVID-19 symptoms in general hospital settings (box 1).

While these recommendations have been specifically applied to supporting the needs of autistic people, it should be emphasised that they may be more broadly beneficial for other groups. For instance, introducing flexibility to regulations may also support individuals with intellectual disability (but not autism), other neurodevelopmental conditions (eg, attention deficit hyperactivity disorder and behavioural problems) and mental health conditions, such as anxiety. Similarly, the provision of accessible healthcare information and communication toolkits would be equally applicable for individuals with sight or hearing loss, or speech and language difficulties. ${ }^{91}$

Moreover, our third recommendation is that triage protocols are urgently reviewed and updated, in consultation with stakeholders, to inform an aligned European strategy on the fair allocation of resources in public health emergencies (box 1). This strategy is essential to prevent the widespread exclusion of autistic people from ICU, to promote better healthcare equality across Europe, and to provide official guidance and support to regions where it is currently unavailable. Joint consultation between ICU clinicians and the autism community could further aid this progress by clarifying the application of triage protocols in everyday clinical practice, reducing the potential for bias to enter into clinical and legislative recommendations, and promoting transparency to ensure that individuals are not deterred from seeking services due to fear of exclusion.

\section{Enhancing access to existing health and social care services}

With the proper resourcing and funding of health and social care systems, the prospective need to implement triage protocols is reduced. After the economic crisis of 2008-13, public spending on health slowed or fell across at least 24 European countries, both in absolute terms and as a share of overall government spending. ${ }^{92}$ In addition, there is very little available evidence to suggest 
the most (cost-)effective ways to provide social care for autistic people. ${ }^{93}$

Despite these issues, many non-emergency health and social care services have not altogether ceased as a result of COVID-19, but instead have been shifted from in-person to remote or online delivery (ie, 'telehealth'). The fast implementation of telehealth in response to COVID-19 could have a positive impact on clinical practice in the longer term, ${ }^{94} 95$ particularly for improving accessibility and reducing costs of health and social care services. For instance, one previous systematic review showed that outcomes of telehealth assessment and interventions for autistic people were broadly comparable to face-to-face consultations and superior to comparison groups who received no consultation at all. ${ }^{96}$ Additionally, telehealth may be particularly beneficial for enabling individuals who live in areas with particular service or specialist staff shortages to access high-quality support from elsewhere. ${ }^{97}$ Thus, even prior to COVID-19, telehealth had been identified as a key area for promoting more effective, accessible and resilient European healthcare systems. ${ }^{98}$

However, there is a lack of research about the most effective and appropriate methods for implementing telehealth services that ensure continuity of care, and more data are needed about which in-person services (particularly in the social care domain) are (or are not) conducive for remote implementation. Therefore, to ensure that telehealth fulfils its future positive potential to improve the quality of healthcare for autistic people and those with intellectual disability, more research is required on how it can be implemented in an accessible and personalised way. ${ }^{99} 100$ For instance, the European Disability Forum recommends that all information is provided in plain, easy-to-read language, alternative methods are provided for those who communicate by different means or who do not have access to certain technologies (eg, video, telephone, email/messaging services), and the accessibility needs of different groups (including younger children) are considered-for example, appropriate sign language interpretation or captioning and symbols. ${ }^{101}$ Some of these recommendations require that the care provider has specialist training on supporting autistic people and those with intellectual disability, and all require future research into their efficacy in everyday clinical practice.

Overall and based on the evidence reported above, our final (and broadest) recommendation is that the impact of COVID-19 on health and social care service provision for autistic people is comprehensively reviewed to inform contingency plans for the safe and effective delivery of services in the short and longer term (box 1). This could include a shift to more community-based care and incorporating greater flexibility to ensure that services can quickly adapt to changing circumstances-for example, reducing the demand for a formal diagnosis of autism as a prerequisite for accessing needs-based support. Furthermore, there is a significant need for high-quality and reliable data ${ }^{75}$ to identify key areas for targeted restructuring and investment for improving health and social care provisions (eg, strategies for earlier detection of support needs and early interventions) for autistic people.

\section{Learning from best practice and future directions}

Though it is of paramount importance to address the barriers for COVID-19 health and social care services highlighted in this review, it should be noted that we also identified good examples of strategies to support autistic people and those with intellectual disability. Many services and individual professionals have made considerable efforts to continue to support autistic people in these unprecedented times and shown incredible adaptability and innovation. For instance, non-profit organisations across Europe have provided comprehensive and accessible online toolkits to support families and regular expert webinars on topics like mental health and coping with uncertainty. ${ }^{23} 102103$ Additionally, some healthcare providers have implemented 24/7 telehealth services and live-in residential care. ${ }^{63}$ Several reasonable adjustments have also been made across Europe for autistic people, including exceptions on wearing face masks in public and allowing increased daily exercise during lockdown periods. Finally, in response to lobbying by non-profit organisations, new and amended guidance on supporting autistic people has started to be released, which we aim to complement and accelerate with the current report.

It is clear there are many additional issues facing autistic people in relation to COVID-19, which were beyond the scope of the current review, but must be investigated in future research. These issues include the impact of isolation; changes in education and employment; public understanding of adjustments to regulations for autistic people; and, now, how earlier policies have impacted on the accessibility of vaccination programmes and strategies. In particular, the mental and physical health impacts of COVID-19 should be assessed, given high reported rates of pandemic-related stressors among families with a child with autism, ${ }^{104-106}$ and possible long-term mental and physical health implications of COVID-19 infection. ${ }^{107} 108$ Furthermore, longitudinal data on health and social care access and the impact of disruptions to education and community facilities before, during and after the COVID-19 pandemic may reveal critical areas for addressing future policy and practice.

\section{Strengths and limitations}

This review represents the first comprehensive analysis of COVID-19 health and social care access for autistic people across 15 European countries, also capturing the lived experiences of over 1300 individuals from the autism community. Nevertheless, our findings must be considered in the context of the following limitations. First, it was not possible to collect information from all European countries in this study and there were important regional differences within countries that were included, in terms of COVID-19 policies and public health strategies. As a result, the reported findings represent an overview, rather than a nuanced analysis, of the current 
situation and approaches of each country. This limitation was somewhat unavoidable, given the constantly evolving situation, in which new sources and data were iteratively published and amended between March and July 2020. Moreover, European countries worst hit by the COVID-19 pandemic (eg, the UK, Spain, Italy) had the most available resources and data, thus making them more eligible for inclusion. Despite this, evidence collated from countries where resources and data were freely accessible, combined with lived experiences from the autism community through survey data, were paramount for informing our recommendations for an aligned European strategy for responding to pandemic situations.

Second, with the exception of triage protocols, we were largely unable to make direct comparisons between countries because each country has different health and social care systems. For instance, some health systems are free to the user, whereas in others a large proportion of the population have private health insurance. ${ }^{109}{ }^{110}$ Similarly, the proportion of social care services provided by the government, non-profit and private organisations varies across Europe. ${ }^{110}$ To capture COVID-19 health and social care access, systematically adjusted for health system variability, it would be necessary to gather long-term data (eg, insurance data) before, during and after the COVID-19 pandemic. However, in this study our primary aim was to collate current policies and guidelines to inform rapid recommendations for improving COVID-19 service access for autistic people prior to potential future peaks of the virus.

Finally, as with the policy review, response rates from the Autism-Europe survey were somewhat biased toward those countries particularly impacted by COVID-19, such as Italy and Spain. Response biases may also have been introduced by the convenience sampling method, the snapshot of time within which the survey was administered and the informant-with the majority of included respondents $(\sim 73 \%)$ being caregivers, who may therefore be more likely to report on behalf of autistic people with particularly high support needs, including children and those with co-occurring intellectual disability (although it was not possible to confirm this on the basis of the available data). Despite this limitation, the inclusion of data on the lived experiences from the autism community was crucial to demonstrate how policy and guidelines were being reflected in real-world practice and to ensure these experiences were reflected in recommendations for enhancing accessibility of services for autistic people.

\section{CONCLUSIONS}

The global COVID-19 pandemic has had an unprecedented impact on European health and social care systems, with supply chains and services forced to adapt rapidly to increased demand. In this review, we identified several significant barriers in access to COVID-19 services for autistic people, despite their increased risk of severe illness and mortality due to factors such as frequently co-occurring physical health conditions, difficulties with symptom identification, and living in residential care. Barriers for accessing COVID-19 services included (1) a lack of accessibility to testing, including difficulties tolerating swab procedures; (2) lack of access to outpatient and inpatient treatment, largely due to differences in communication needs (eg, difficulty using telephone); (3) ICU triage protocols that may directly or indirectly exclude individuals from lifesaving treatment; and (4) abrupt interruptions to standard health and social care, including mental health interventions. Considering the evidence reported, we provide specific recommendations for an aligned European strategy to reduce health and social care inequalities in public health emergencies (box 1 ), which require particularly urgent consideration to enhance the future care of autistic people both during and beyond the pandemic.

\section{Author affiliations}

'Department of Forensic and Neurodevelopmental Sciences, King's College London, London, UK

${ }^{2}$ Department of Psychology, King's College London, London, UK

${ }^{3}$ Department of Applied Psychology: Health, Development, Enhancement, and Intervention, University of Vienna, Vienna, Austria

${ }^{4}$ Autism Research Centre, Department of Psychiatry, University of Cambridge, Cambridge, UK

${ }^{5}$ Autism Europe, Brussels, Belgium

${ }^{6}$ South London and Maudsley NHS Foundation Trust, (SLaM), London, UK

${ }^{7}$ Centre for Brain and Cognitive Development, Birkbeck University of London,

London, UK

${ }^{8}$ Autistica, London, UK

${ }^{9}$ Department of Anaesthesia, Our Lady's Hospital, Navan, Meath, Ireland

${ }^{10}$ Department of Tropical and Parasitic Diseases, Medical University of Gdansk, Gdansk, Poland

${ }^{11}$ Department of Child \& Adolescent Psychiatry, King's College London, London, UK

${ }^{12}$ Donders Institute for Brain, Cognition and Behavior, Department of Cognitive Neuroscience, Radboud University Nijmegen Medical Centre, Nijmegen, The

Netherlands

${ }^{13}$ Karakter Child and Adolescent Psychiatry, University Center, Nijmegen, The Netherlands

${ }^{14}$ Discipline of Psychiatry, Trinity Translational Medicine Institute, Trinity College, Dublin, Ireland

${ }^{15}$ Sackler Institute for Translational Neurodevelopment, King's College London, London, UK

Acknowledgements We would like to thank the AIMS-2-TRIALS Clinical Trials Network and Early Career Researchers in Autism Network for their contributions and support for this project. We particularly acknowledge: Roderik Plas, Katrien van den Bosch, Evdokia Anagnostou, Kathrin Hippler, Sonja Metzler, Sofie Boterberg, Herbert Roeyers, Guillame Dumas, Frédérique Bonnet-Brilhault, Louise Poutska, Christine Freitag, Filippo Muratori, Eugenia Conti, Erik Mulder, Giorgia Bussu, Anne Smit, Elke de Jonge, Manon Krol, Ciara Molloy, Julia Koziel, Célia Rasga, Sonija Luzi, Monica Burdeus, Laura Gisbert, Antonia San José Cáceres, Eleni Kroupi, Covadonga Martinez, Alvaro Beja, Miriam Rivero Contreras, María Manzano Arjona, Clara Janisel Fernández Álvarez, Ruth Campos, Alicia Alcon, Jorge Lugo, Imanol Setien, Gara Arteaga, Ana Blazquez and Dominika Zofia Wojcik.

Collaborators AIMS-2-TRIALS ECRAN; AIMS-2-TRIALS Consortium.

Contributors $\mathrm{BO}$, JT and AR led on coordinating the project, analysis and writing the manuscript. $A B$ and $C T$ provided de-identified secondary data from the Autism-Europe survey. TC, EJ, JC, ES, JKB, LG and DGMM led on the study concept and development. MD, PV and AW provided additional study sources. All authors critically reviewed the manuscript and agreed on submission.

Funding This project was supported by the Innovative Medicines Initiative 2 Joint Undertaking under grant agreement No 777394. This Joint Undertaking receives support from the European Union's Horizon 2020 research and innovation 
programme and EFPIA and SFARI, Autistica, AUTISM SPEAKS. The views expressed are those of the author(s) and not necessarily those of the IMI 2JU.

Map disclaimer The depiction of boundaries on this map does not imply the expression of any opinion whatsoever on the part of BMJ (or any member of its group) concerning the legal status of any country, territory, jurisdiction or area or of its authorities. This map is provided without any warranty of any kind, either express or implied.

Competing interests JB reports personal fees from Servier, Angelini, Medice, F. Hoffmann-La Roche, Takeda/Shire, and Janssen / J\&J. DM reports personal fees from Hoffmann-La Roche. JT reports personal fees from Hoffmann-La Roche. TC reports personal fees from F. Hoffmann-La Roche, Servier, Sage Publications, Guildford Publications. For all authors above, the present work is unrelated to these relationships.

\section{Patient consent for publication Not required.}

Provenance and peer review Not commissioned; externally peer reviewed.

Data availability statement Data are available upon reasonable request. All data relevant to the study are included in the article or uploaded as supplementary information. Should further details or materials be required, please contact the corresponding author.

Supplemental material This content has been supplied by the author(s). It has not been vetted by BMJ Publishing Group Limited (BMJ) and may not have been peer-reviewed. Any opinions or recommendations discussed are solely those of the author(s) and are not endorsed by BMJ. BMJ disclaims all liability and responsibility arising from any reliance placed on the content. Where the content includes any translated material, BMJ does not warrant the accuracy and reliability of the translations (including but not limited to local regulations, clinical guidelines, terminology, drug names and drug dosages), and is not responsible for any error and/or omissions arising from translation and adaptation or otherwise.

Open access This is an open access article distributed in accordance with the Creative Commons Attribution Non Commercial (CC BY-NC 4.0) license, which permits others to distribute, remix, adapt, build upon this work non-commercially, and license their derivative works on different terms, provided the original work is properly cited, appropriate credit is given, any changes made indicated, and the use is non-commercial. See: http://creativecommons.org/licenses/by-nc/4.0/.

\section{ORCID iDs}

Julian Tillmann http://orcid.org/0000-0001-9574-9855

Tony Charman http://orcid.org/0000-0003-1993-6549

\section{REFERENCES}

1 World Health Organization. Coronavirus disease (COVID-19) Situation Report [Internet], 2020. Available: https://www.who.int/ docs/default-source/coronaviruse/situation-reports/20200614covid-19-sitrep-146.pdf?sfvrsn=5b89bdad_4

2 et alBayer R, Bernheim RG, Crawley LM. Ethical Considerations for Decision Making Regarding Allocation of Mechanical Ventilators during a Severe Influenza Pandemic or Other Public Health Emergency [Internet], 2011. Available: https://www.cdc.gov/about/ advisory/pdf/VentDocument_Release.pdf

3 Emanuel EJ, Persad G, Upshur R, et al. Fair allocation of scarce medical resources in the time of Covid-19. N Engl J Med 2020;382:2049-55.

4 Hale T, Angrist N, Kira B. Variation in government responses to COVID-19 2020.

5 European Centre for Disease Prevention and Control. Coronavirus disease 2019 (COVID-19) in the EU/ EEA and the UK - eighth update 8 April 2020 [Internet]. Vol. 2019, 2020. Available: https:// www.ecdc.europa.eu/sites/default/files/documents/covid-19-rapidrisk-assessment-coronavirus-disease-2019-eighth-update-8-april2020.pdf

6 Pellicano E, Stears M. The hidden inequalities of COVID-19. Autism 2020;24:1309-10.

7 The Center for Public Integrity. State policies may send people with disabilities to the back of the line for ventilators [Internet] 2020. Available: https://publicintegrity.org/health/coronavirus-andinequality/state-policies-may-send-people-with-disabilities-to-theback-of-the-line-for-ventilators/

8 MacKay T, Boyle J, Connolly M. The Microsegmentation of the Autism Spectrum: Economic and Research Implications for Scotland [Internet. Edinburgh: The Scottish Government, 2018.
https://strathprints.strath.ac.uk/67058/1/MacKay_etal_SG2018_ The_microsegmentation_of the_autism_spectrum.pdf

9 Charman T, Jones CRG, Pickles A, et al. Defining the cognitive phenotype of autism. Brain Res 2011:1380:10-21.

10 Croen LA, Zerbo O, Qian Y, et al. The health status of adults on the autism spectrum. Autism 2015;19:814-23.

11 Flygare Wallén E, Ljunggren G, Carlsson AC, et al. High prevalence of diabetes mellitus, hypertension and obesity among persons with a recorded diagnosis of intellectual disability or autism spectrum disorder. J Intellect Disabil Res 2018;62:269-80.

12 Jordan RE, Adab P, Cheng KK. Covid-19: risk factors for severe disease and death. BMJ 2020;368:m1198.

13 Doherty M, Sullivan JD, Neilson SD. Barriers to healthcare for autistic adults: Consequences \& policy implications. A crosssectional study. medRxiv 2020 https://www.medrxiv.org/content/ early/2020/04/06/2020.04.01.20050336

14 Mason D, Ingham B, Urbanowicz A, et al. A systematic review of what barriers and facilitators prevent and enable physical healthcare services access for autistic adults. J Autism Dev Disord 2019;49:3387-400.

15 Nicolaidis C, Raymaker DM, Ashkenazy E, et al. "Respect the way I need to communicate with you": Healthcare experiences of adults on the autism spectrum. Autism 2015;19:824-31.

16 NHS England. Supporting patients of all ages who are unwell with coronavirus (COVID-19) in mental health, learning disability, autism, dementia and specialist inpatient facilities [Internet]. Report No.: 30 April, 2020. Available: https://www.england.nhs. uk/coronavirus/wp-content/uploads/sites/52/2020/04/C0290 Supporting-patients-who-are-unwell-with-COVID-19-in-MHLDAsettings.pdf

17 Care Quality Commission. CQC publishes data on deaths of people with a learning disability [Internet]. Available: https://www.cqc. org.uk/news/stories/cqc-publishes-data-deaths-people-learningdisability

18 Office for National Statistics. Deaths registered weekly in England and Wales, provisional [Internet]. Available: https://www.ons.gov.uk/ peoplepopulationandcommunity/birthsdeathsandmarriages/deaths/ datasets/weeklyprovisionalfiguresondeathsregisteredinenglanda ndwales

19 World Health Organisation Regional Office for Europe. Strengthening the health system response to COVID-19: Preventing and managing the COVID-19 pandemic across long-term care services in the WHO European Region (21 May 2020) [Internet], 2020. Available: https://apps.who.int/iris/bitstream/handle/10665/ 333067/WHO-EURO-2020-804-40539-54460-eng.pdf?sequence $=$ 1 \&isAllowed $=y$

20 World Health Organisation. Disability considerations during the COVID-19 outbreak [Internet], 2020. Available: https://www.who.int/ publications/i/item/WHO-2019-nCoV-Disability-2020-1

21 Alexander RT. People with Intellectual Disability and Mental Health/ Behavioural Problems: Guidance on COVID-19 for Inpatient Settings IInternet. Norwich: RADiANT, 2020. http://radiant.nhs.uk/uploads/ 2/7/2/5/27254761/alexander_2020_guidance_on_covid-19_for_ inpatient id settings.pdf

22 Inclusion Europe. Coronavirus (COVID-19) pandemic [Internet], 2020. Available: https://www.inclusion-europe.eu/coronaviruspandemic/

23 Autism Europe. The autism community mobilizes itself to face COVID-19 [Internet]. Available: https://www.autismeurope.org/blog/ 2020/03/20/the-autism-community-mobilizes-itself-to-face-covid19/ [Accessed 30 Jun 2020].

24 National Institute for Public Health and the Environment. Policy on testing for novel coronavirus disease (COVID-19) [Internet], 2020. Available: https://www.rivm.nl/en/node/154261

25 Sciensano. Hospital procedure for approaching a patient with possible/ confirmed COVID-19 [Internet], 2020. Available: https:// covid-19.sciensano.be/sites/default/files/Covid19/COVID-19 procedure_hospitals_NL.pdf

26 UK Department of Health and Social Care. Coronavirus (COVID-19): getting tested [Internet], 2020. Available: https://www.gov.uk/ guidance/coronavirus-covid-19-getting-tested

27 Buescher AVS, Cidav Z, Knapp M, et al. Costs of autism spectrum disorders in the United Kingdom and the United States. JAMA Pediatr 2014;168:721-8.

28 Shinn AK, Viron M. Perspectives on the COVID-19 pandemic and individuals with serious mental illness. $J$ Clin Psychiatry 2020;81:20com13412.

29 World Health Organisation. Rational use of personal protective equipment for coronavirus disease 2019 (COVID-19) [Internet], 2020. Available: https://apps.who.int/iris/bitstream/handle/10665/ 331215/WHO-2019-nCov-IPCPPE_use-2020.1-eng.pdf 
30 Organisation for Economic Development and Cooperation. OECD Policy Responses to Coronavirus (COVID-19) - Testing for COVID-19: A way to lift confinement restrictions [Internet], 2020. Available: https://www.oecd.org/coronavirus/policy-responses/ testing-for-covid-19-a-way-to-lift-confinement-restrictions89756248/\#endnotea0z16

31 Health Protection Surveillance Centre. Interim Public Health, Infection Prevention \& Control Guidelines on the Prevention and Management of COVID-19 Cases and Outbreaks in Residential Care Facilities [Internet], 2020. Available: https://www.hpsc.ie/a-z/ respiratory/coronavirus/novelcoronavirus/guidance/outbreakmana gementguidance/RCF guidance document.pdf

32 Uljarević M, Baranek G, Vivanti G, et al. Heterogeneity of sensory features in autism spectrum disorder: challenges and perspectives for future research. Autism Res 2017;10:703-10.

33 Boulter C, Freeston M, South M, et al. Intolerance of uncertainty as a framework for understanding anxiety in children and adolescents with autism spectrum disorders. J Autism Dev Disord 2014;44:1391-402.

34 European Centre for Disease Prevention and Control. Diagnostic testing and screening for SARS-CoV-2 [Internet], 2020. Available: https://www.ecdc.europa.eu/en/covid-19/latest-evidence/ diagnostic-testing

35 Istituto Superiore di Sanit. Interim Indications for appropriate support of people on the autistic spectrum in the current emergency scenario SARS-CoV-2 [Internet]. Report No.: 30 March, 2020. Available: https://www.iss.it/documents/20126/0/Rapporto+ISS+ COVID-19+n.+8+autismo+\%282\%29.pdf/c558b34e-1bc9-c8680c75-0030f8299bca?t=1585757457709

36 Agency for Care and Health. Covid-19 - Mental health care [Internet], 2020. Available: https://www.zorg-en-gezondheid.be/ corona-richtlijnen-voor-zorgprofessionals

37 European Disability Forum. Open letter to leaders at the EU and in EU countries: COVID-19 - disability inclusive response [Internet]. Available: http://edf-feph.org/newsroom/news/open-letter-leaderseu-and-eu-countries-covid-19-disability-inclusive-response

38 NHS Providers. The impact of COVID-19 on mental health trusts in the NHS [Internet], 2020. Available: https://nhsproviders.org/media/ 689590/spotlight-on-mental-health.pdf

39 Council of Europe. Bioethics COVID-19: Selected resources by country [Internet], 2020. Available: https://www.coe.int/en/web/ bioethics/selected-resources-by-country/

40 Federation of Medical Specialists. Guidance: Triage home treatment versus referral to hospital in elderly patients with (suspected) COVID-19 [Internet]. Report No.: 3, 2020. Available: https://translate.google.com/translate?hl=en\&sl= nl\&u=https://www.demedischspecialist.nl/sites/default/files/ Leidraad\%2520triage\%2520thuisbehandeling\%2520versus\% 2520 verwijzen\%2520oudere\%2520pati\%25C3\%25ABnt\% 2520 met\%2520verdenking\%2520COVID-19.pdf\&prev=search\& pto=aue

41 Joebges S, Biller-Andorno N. Ethics guidelines on COVID-19 triagean emerging international consensus. Crit Care 2020;24:201.

42 Ethics Working Group of the Austrian Society for Anaesthesiology Resuscitation and Intensive Care. Allocation of intensive care medical resources: Occasion of the Covid 19 pandemic [Internet], 2020. Available: https://www.oegari.at/web files/cms daten/covid19_ressourcenallokation_gari-statement_v1.7_final_2020-03-17.pdf

43 Austria Bioethics Commission. Management of scarce resources in healthcare in the context of the COVID-19 pandemic: Opinion of the Bioethics Commission [Internet], 2020. Available: https://rm.coe.int/ management-scarce-resources/16809e40f1

44 Azoulay Élie, Beloucif S, Guidet B, et al. Admission decisions to intensive care units in the context of the major COVID-19 outbreak: local guidance from the COVID-19 Paris-region area. Crit Care 2020;24:293.

45 German Interdisciplinary Association for Intensive Care and Emergency Medicine. Decisions on the allocation of intensive care medicine resources in the context of the COVID-19 pandemic (Version 2) [Internet], 2020. Available: https://www. awmf.org/uploads/tx_szleitlinien/040-013I_S1_Zuteilungintensivmedizinscher-Ressourcen-COVID-19-Pandemie-Klinischethische_Empfehlungen_2020-04.pdf

46 Department of Health Ireland. Ethical Framework for DecisionMaking in a Pandemic [Internet], 2020. Available: https://www.gov. ie/en/publication/dbf3fb-ethical-framework-for-decision-making-ina-pandemic/

47 Italian Society of Anaesthesia Analgesia Resuscitation and Intensive Care. Clinical Ethics Recommendations for the Allocation of Intensive Care Treatments in exceptional, resource-limited circumstances - Version n. 1 Posted on March, 16, 2020: 1-8.
48 Clarfield AM, Dwolatzky T, Brill S, et al. Israel AD hoc COVID-19 Committee: guidelines for care of older persons during a pandemic. J Am Geriatr Soc 2020;68:1370-5.

49 Cassidy SA, Nicolaidis C, Davies B, et al. An expert discussion on autism in the COVID-19 pandemic. Autism in Adulthood 2020;2:106-17.

50 Health Service Journal. Learning disabilities patients told they may be 'too frail' for mechanical ventilation if they get covid-19 [Internet] Available: https://www.hsj.co.uk/coronavirus/learning-disabilitiespatients-told-they-may-be-too-frail-for-mechanical-ventilation-ifthey-get-covid-19/7027318.article [Accessed 4 Apr 2020].

51 Tavernor L, Barron E, Rodgers J, et al. Finding out what matters: validity of quality of life measurement in young people with ASD. Child Care Health Dev 2013;39:592-601.

52 Hodge and Allen Solicitors. NICE amends COVID-19 critical care guidelines after judicial review challenge [Internet]. Vol. 31. Available: https://www.hja.net/press-releases/nice-amends-covid19-critical-care-guideline-after-judicial-review-challenge/

53 Mencap. Mencap responds to new NICE COVID-19 guidance [Internet]. Available: https://www.mencap.org.uk/press-release/ mencap-responds-deeply-troubling-new-nice-covid-19-guidance

54 National Institute for Health and Care Excellence. COVID-19 rapid guideline: critical care in adults [Internet]. Report No.: 20 March, 2020. Available: https://www.nice.org.uk/guidance/ng159/ resources/covid19-rapid-guideline-critical-care-in-adults-pdf66141848681413

55 Montgomery J, Stokes-Lampard HJ, Griffiths MD, et al. Assessing whether COVID-19 patients will benefit from critical care, and an objective approach to capacity challenges during a pandemic: an intensive care Society clinical guideline. J Intensive Care Soc 2020:175114372094853. doi:10.1177/1751143720948537

56 NVAVG. Guidance referral of the adult patient with an intellectual disability and (suspected) COVID-19 [Internet]. 2020. Report No.: 15 April. Available: https://translate.googleusercontent.com/translate c?depth=1\&hl=en\&prev=search\&pto=aue\&rurl=translate.google com\&sl=nl\&sp=nmt4\&u=https://nvavg.nl/wp-content/uploads/2020/ 04/NVAVG_Covid-19_leidraad.pdf\&usg=ALkJrhjFUhRYRyvgthG2 T1ECCGY-7qvnaA

57 Royal Dutch Medical Association. Scenario Triage based on non-medical considerations for IC inclusion at the time of phase 3 in the COVID-19 pandemic [Internet], 2020. Available: https://www.rijksoverheid.nl/binaries/rijksoverheid/ documenten/publicaties/2020/06/16/draaiboek-triageop-basis-van-niet-medische-overwegingen-voor-icopname-ten-tijde-van-fase-3-in-de-covid-19-pandemie/ draaiboek-triage-op-basis-van-niet-medische-overwegingenvoor-ic-opname-ten-tijde-van-fase-3-in-de-covid-19-pandemie. pdf

58 The Spanish Society of Intensive Critical Medicine and Coronary Units. Plan de contingencia para loc servicios de medicina intensiva frente a la pandemia COVID-19 [Internet], 2020. Available: https:// www.semicyuc.org/covid19_files/Plan_de_Contingencia_COVID-19. pdf

59 Devereaux AV, Dichter JR, Christian MD, et al. Definitive care for the critically ill during a disaster: a framework for allocation of scarce resources in mass critical care: from a task force for mass critical care Summit meeting, January 26-27, 2007, Chicago, IL. Chest 2008;133:51S-66. doi:10.1378/chest.07-2693

60 Biddison LD, Berkowitz KA, Courtney B, et al. Ethical considerations: care of the critically ill and injured during pandemics and disasters: chest consensus statement. Chest 2014:146:e145S-55. doi:10.1378/chest.14-0742

61 Spanish Bioethics Committee. Report of the Spanish Bioethics Committee on bioethics aspects of the prioritisation of sanitary resources in the context of the coronavirus crisis [Internet], 2020. Available: http://assets.comitedebioetica.es/files/documentacion/ Informe CBE- Priorizacion de recursos sanitarios-coronavirus CBE. pdf

62 Spanish Ministry of Health. Ministry of Health report on ethical issues in pandemic situations: SARS-CoV-2 [Internet]. 2020. Report No.: 3 April. Available: https://rm.coe.int/pandemic-covid-19-spaineng/16809e3a78

63 Arango C. Lessons learned from the coronavirus health crisis in Madrid, Spain: how COVID-19 has changed our lives in the last 2 weeks. Biol Psychiatry 2020;88:e33-4.

64 Autism Spain. Autism Spain prepares a document of de-escalation proposals for entities and services specialized in people with autism and their families [Internet], 2020. Available: http://www.autismo. org.es/actualidad/articulo/autismo-espana-elabora-un-documentode-propuestas-de-desescalada-para-entidades 
65 NHS Digital. Autism Statistics [Internet], 2019. Available: https:// digital.nhs.uk/data-and-information/publications/statistical/autismstatistics/autism-statistics

66 European Association of Service providers for Persons with Disabilities. The impact of COVID-19 on disability services in Europe [Internet], 2020. Available: https://www.easpd.eu/sites/default/ files/sites/default/files/Publications2020/impact of covid-19 on disability_services_in_europe_a_first_snapshot.pdf

67 National Institute for Health and Disability Insurance. Medical care and benefits insurance: exceptional measures to combat COVID 19 [Internet], 2020. Available: https://www.riziv.fgov.be/nl/covid19/ Paginas/default.aspx

68 Social Care Institute for Excellence. Understanding the impact of COVID-19 responses on citizens [Internet], 2020. Available: https://www.scie.org.uk/care-providers/coronavirus-covid-19/ commissioning/impact-on-citizens

69 Cautreels M, Heiremans M. Corona pushes disabled care into the corner where the blows fall [Internet], 2020. Available: https:// sociaal.net/opinie/corona-duwt-gehandicaptenzorg-in-hoek-waarde-klappen-vallen/

70 Ministry of Health Wellbeing and Sports. New visitors scheme for care for the disabled and mental health care [Internet], 2020. Available: https://www.rijksoverheid.nl/onderwerpen/coronaviruscovid-19/nieuws/2020/03/23/nieuwe-bezoekersregelinggehandicaptenzorg-en-ggz

71 European Centre for Disease Prevention and Control. Surveillance of COVID-19 at longterm care facilities in the EU/EEA [Internet], 2020. Available: https://www.ecdc.europa.eu/sites/default/files/ documents/covid-19-long-term-care-facilities-surveillanceguidance.pdf

72 UK Department of Health and Social Care. Update on policies for visiting arrangements in care homes [Internet]. Report No.: 31 July, 2020. Available: https://www.gov.uk/government/publications/ visiting-care-homes-during-coronavirus/update-on-policies-forvisiting-arrangements-in-care-homes

73 UK Department of Health and Social Care. Care Act easements: guidance for local authorities [Internet], 2020. Available: https:// www.gov.uk/government/publications/coronavirus-covid-19changes-to-the-care-act-2014/care-act-easements-guidance-forlocal-authorities\#purpose-of-the-easements

74 Care Quality Commission. The Care Act and the 'easements' to it [Internet], 2020. Available: https://www.cqc.org.uk/guidanceproviders/adult-social-care/care-act-easements-it

75 et alHodgson K, Grimm F, Vestesson E. Briefing: Adult social care and COVID-19 Assessing the impact on social care users and staff in England so far [Internet]. 2020. Report No.: July. Available: https://www.health.org.uk/publications/reports/adult-social-careand-covid-19-assessing-the-impact-on-social-care-users-andstaff-in-england-so-far

76 World Health Organization. COVID-19 Strategy Update 4th April 2020 [Internet], 2020. Available: https://www.who.int/docs/defaultsource/coronaviruse/covid-strategy-update-14april2020.pdf? sfvrsn=29da3ba0_19

77 European Commission. Testing kits for COVID-19: What is the EU doing? [Internet], 2020. Available: https://ec.europa.eu/health/ sites/health/files/preparedness_response/docs/testingkits_ factsheet.pdf

78 European Centre for Disease Prevention and Control. An overview of the rapid test situation for COVID-19 diagnosis in the EU / EEA [Internet], 2020. Available: https://www.ecdc.europa.eu/sites/ default/files/documents/Overview-rapid-test-situation-for-COVID19-diagnosis-EU-EEA.pdf

79 European Commission. COVID-19 EU recommendations for testing strategies, 2020.

80 DuBois D, Ameis SH, Lai M-C, et al. Interoception in autism spectrum disorder: a review. Int J Dev Neurosci 2016;52:104-11.

81 Kinnaird E, Stewart C, Tchanturia K. Investigating alexithymia in autism: a systematic review and meta-analysis. Eur Psychiatry 2019;55:80-9.

82 Williams E, Bond K, Zhang B, et al. Saliva as a noninvasive specimen for detection of SARS-CoV-2. J Clin Microbiol 2020;58:e00776-20.

83 To KK-W, Tsang OT-Y, Leung W-S, et al. Temporal profiles of viral load in posterior oropharyngeal saliva samples and serum antibody responses during infection by SARS-CoV-2: an observational cohort study. Lancet Infect Dis 2020;20:565-74.

84 Pratt K, Baird G, Gringras P. Ensuring successful admission to hospital for young people with learning difficulties, autism and challenging behaviour: a continuous quality improvement and change management programme. Child Care Health Dev 2012;38:789-97.
85 World Health Organisation. Strengthening the health system response to COVID-19 in the WHO transmission scenarios: Action points for the WHO European Region [Internet]. Report No.: 01 April, 2020. Available: https://www.euro.who.int/ data/assets/pdf file/0005/436352/strengthening-health-system-response-COVID19-WHO-transmission-scenarios.pdf

86 Truog RD, Mitchell C, Daley GQ. The Toughest Triage - Allocating Ventilators in a Pandemic. N Engl J Med 2020;382:1973-5.

87 New York State Task Force on Life and the Law \& New York State Department of Health. Ventilator Allocation Guidelines [Internet] Report No.: November, 2015. Available: https://www.health.ny. gov/regulations/task_force/reports_publications/docs/ventilator_ guidelines.pdf

88 European Court of Human Rights. European Convention on Human Rights [Internet]. Strasbourg, 2010. Available: https://www.echr.coe. int/Documents/Convention_ENG.pdf

89 United Nations. Convention on the rights of persons with disabilities, 2008.

90 International Disability Alliance. An Open Letter to the World Health Organisation [Internet], 2020. Available: http://www.internationaldis abilityalliance.org/sites/default/files/ida_letter_to_who_march_31_ 2020.pdf

91 Grote H, Izagaren F. Covid-19: the communication needs of D/ deaf healthcare workers and patients are being forgotten. BMJ 2020;369:m2372.

92 Thomson S, Figueras J, Evetovits T. Economic crisis. health systems and health in Europe: impact and implications for policy [Internet] $2014 \mathrm{https}: / /$ www.euro.who.int/_data/assets/pdf_file/ 0008/257579/Economic-crisis-health-systems-Europe-impactimplications-policy.pdf?ua $=1$

93 Smith E, Kenny L, Harper G. Action Briefing: social care, 2020.

94 Galletly C. Psychiatry in the COVID-19 era. Aust N Z J Psychiatry 2020;54:447-8.

95 Vieta E, Pérez V, Arango C. Psychiatry in the aftermath of COVID-19. Rev Psiquiatr y Salud Ment [Internet], 2020. Available: http://www.sciencedirect.com/science/article/pii/ S188898912030029X

96 Sutherland R, Trembath D, Roberts J. Telehealth and autism: a systematic search and review of the literature. Int J Speech Lang Pathol 2018;20:324-36.

97 Little LM, Wallisch A, Pope E, et al. Acceptability and cost comparison of a telehealth intervention for families of children with autism. Infants Young Children 2018;31:275-86.

98 European Commission. Strategic Plan 2016-2020: DG Health and Food Safety [Internet], 2017. Available: https://ec.europa.eu/info/ sites/info/files/strategic-plan-2016-2020-dg-sante_en_0.pdf

99 Office of the Federal Council for the Mental Health Professions. Mental Health Care provided remotely by GGZ-professionals in the context of the Covid-19quarantine measures [Internet], 2020. Available: https://overlegorganen.gezondheid.belgie.be/sites/ default/files/documents/20200401-bureaufrggzb-nota_nl_covid-19. pdf

100 Ameis SH, Lai M-C, Mulsant BH, et al. Coping, fostering resilience, and driving care innovation for autistic people and their families during the COVID-19 pandemic and beyond. Mol Autism 2020;11:61.

101 Noel K, Ellison B. Inclusive innovation in telehealth. NPJ Digit Med 2020;3:89.

102 AsIAm. AsIAm and COVID-19, 2020

103 Autistica. Coronavirus and autism [Internet], 2020. Available: https:// www.autistica.org.uk/what-is-autism/coronavirus

104 Pearcey S, Shum A, Waite P. Supplementary Report 03: Differences in pandemic anxiety, parent/carer stressors and reported needs between parent/carers of children with and without ASD; Change over time in mental health for children with ASD. [Internet], 2020. Available: https://emergingminds.org.uk/wp-content/uploads/2020/ 07/Co-SPACE-supplementary-report-03-final.pdf

105 White LC, Law JK, Daniels AM, et al. Brief report: impact of COVID-19 on individuals with ASD and their caregivers: a perspective from the spark cohort. J Autism Dev Disord 2021. doi:10.1007/s10803-020-04816-6. [Epub ahead of print: 02 Jan 2021].

106 Summers J, Baribeau D, Mockford M, et al. Supporting children with neurodevelopmental disorders during the COVID-19 pandemic. J Am Acad Child Adolesc Psychiatry 2021;60:2-6.

107 Asadi-Pooya AA, Simani L. Central nervous system manifestations of COVID-19: a systematic review. J Neurol Sci 2020;413:116832.

108 D'Agostino A, Demartini B, Cavallotti S, et al. Mental health services in Italy during the COVID-19 outbreak. Lancet Psychiatry 2020;7:385-7. 
109 European Parliament. Health Care Systems in the EU: A Comparative Study [Internet], 1998. Available: https://www.europarl. europa.eu/workingpapers/saco/pdf/101_en.pdf

110 Robertson R, Gregory S, Jabbal J. The social care and health systems of nine countries [Internet], 2014. Available: https://www. kingsfund.org.uk/sites/default/files/media/commission-backgroundpaper-social-care-health-system-other-countries.pdf

111 Mencap. Coronavirus: Information about going to hospital [Internet], 2020. Available: https://www.mencap.org.uk/adviceand-support/coronavirus-covid-19/coronavirus-information-aboutgoing-hospital

112 Widgit. Critical Care Covid-19 Communication Chart [Internet], 2020. Available: https://www.widgit.com/products/health/covid19communication-chart.htm

113 NHS England. COVID-19 Grab and Go Guide - Form [Internet], 2020. Available: https://www.england.nhs.uk/coronavirus/wp-
content/uploads/sites/52/2020/03/C0381-nhs-covid-19-grab-andgo-lda-form.pdf

114 House of Lords Hansard. Covid-19: Social Care Services [Internet]. Vol. 803, 2020. Available: https://hansard.parliament.uk/Lords/ 2020-04-23/debates/0D93005E-2D8C-4994-98A0-AABD6341841A/ Covid-19SocialCareServices?highlight=covid\#contribution872EF5DC-BE3B-4042-9C19-723E54CB19E8

115 NHS England. Clinical guide for front line staff to support the management of patients with a learning disability, autism or both during the coronavirus pandemic - relevant to all clinical specialities [Internet]. Report No.: 24 March Version 1, 2020. Available: https:// www.england.nhs.uk/coronavirus/wp-content/uploads/sites/52/ 2020/03/C0031_Specialty-guide_LD-and-coronavirus-v1_-24March.pdf 